\title{
PROJECT MANAGEMENT KNOWLEDGE RETRIEVAL: PROJECT CLASSIFICATION
}

\author{
Solvita Bērziša \\ Riga Technical University, Faculty of Computer Science and Information Technology \\ 1/3 Meza, Riga, LV 1048, Latvia \\ Ph.: +(371)26301110, e-mail: berzisa@gmail.com
}

\begin{abstract}
Project management knowledge contains a wide range of information that can be accumulated from theory and practice. This knowledge is not always readily available to project manager and that can leave a significant impact on project management efficiency and success. Therefore, this knowledge is necessary to store in the project management knowledge repository and then to retrieve it when necessary. To find this knowledge it is necessary to define attributes for searching relevant projects and knowledge associated with these projects. The objective of this paper is to develop a set of project classification attributes that can be used to describe project characteristics and use them in similarity definition. The project classification attributes are defined as a part of the architecture of project management knowledge retrieval. They are identified by analyzing several project management methodologies and are validated by classifying twenty two empirical information technology projects.
\end{abstract}

Keywords: project management knowledge, project classification, knowledge retrieval

\section{Introduction}

Project management (PM) knowledge includes a wide range of information that describes PM data, actions and processes. Use of the accumulated PM knowledge improves effectiveness and success of the project and PM [1][2][3] and reduces possibility of typical errors. Knowledge can be obtained from both theory and practice. Methodologies (e.g. PMBOK [4], PRINCE2 [5]), frameworks (e.g. RUP [6], MSF [7], SCRUM [8]), standards (e.g., ISO 9001 [9], CMMI[10], ISO/IEC, COBIT [11], ITIL [12]) and other guidelines provide the theoretical PM knowledge, but the practical PM knowledge is available from previous projects. This knowledge should to be stored and then retrieved for usage. In order to provide a project manager with actual knowledge it is necessary to find similar projects during the knowledge retrieval process. A project similarity could be determined by comparing project and project environment attributes.

The objective of this paper is to develop a set of the main project classification attributes that can be used to describe the project similarity during the PM knowledge retrieval process. Case-based reasoning (CBR) principles are used for the knowledge retrieval in the PM knowledge retrieval architecture. This architecture ensures theoretical and practical PM knowledge storage in the repository and knowledge retrieval according to the knowledge search area, the project attributes and similarity measurements of the project attributes. The proposed set of project attributes will provide project usage area independent project classification and similarity measurements.

In existing research on project classification focuses on project success characteristics and projects are classified according to the following characteristics: software vs. hardware, project scope, project outcome, technology uncertainty, type of usage, level of operation and type of basic technology [13]. Project also can be classified using two dimensions: technological uncertainty and complexity [14]. Classification using the method of working and the objective clarity has been proposed by [15]. In [16] three dimensions are used for project classification: customer, project and project keywords. These existing classifications are general and slightly subjective, but for the measurement of project similarity more 
detailed and specific classification attributes are needed. For this reasons, the set of project classification attributes has been elaborated in this paper.

This paper is divided in four sections. The material and method section has description of the PM knowledge retrieval architecture, importance of the project attribute in the PM knowledge retrieval and descriptive source of the project attribute. The set of the main project classification attributes is represented in the result section. An example of project classification according to the defined project attributes is shown in the discussion section and conclusions are provided in the last section.

\section{Architecture of PM knowledge retrieval}

\section{Materials and methods}

In order to support knowledge utilization in the PMIS configuration, the architecture of PM knowledge retrieval is elaborated in [17] and shown in Fig.1. This architecture has already been used for other PM knowledge retrieval. A principle of the CBR [18] has been used in design of the architecture of PM knowledge retrieval. CBR consists of the case library and four-step process: retrieve, reuse, revise and retain. The cases in PM knowledge are a) empirical knowledge $C_{j}, j=1, \ldots, m$, that previously have been used in projects and b) PM methodologies, standards and best practices $H_{i}, i=1, \ldots, p$. The cases can be described by the structured PM description in form of XCPM scheme [19]. Data structure, data and processes description have been ensured by this XCPM scheme. Also store of unstructured knowledge $D$ has been allowed in the library.

The CBR process is managed using the client, which has three main modules. The first module is used to describe a new case using the set of project attributes $A_{j+1}$, where $j+1$ is used to identify the new case. The retrieve step is performed by the information retrieval module that is used to find the similar cases in the theoretical and practical case descriptions $\left(P_{t}^{H}\right.$ and $P_{t}^{C}$ ) according to the information search knowledge area $M_{s}$ (e.g., risk management) and the defined similarities $L_{k}, k=1, \ldots, n$. The sets of similar cases according to the new case $j+1$ and the search knowledge area $M_{s}$ are denoted by $\mathbf{H}_{\mathbf{j}+\mathbf{1}, \mathbf{s}}$, and $\mathbf{C}_{\mathbf{j + 1}, \mathbf{s}}$ ' for theoretical and empirical knowledge, respectively, is the result of information retrieval. The information processing and display module performs CBR reuse and revise steps. This module collects and processes gathered information and displays it to the user.

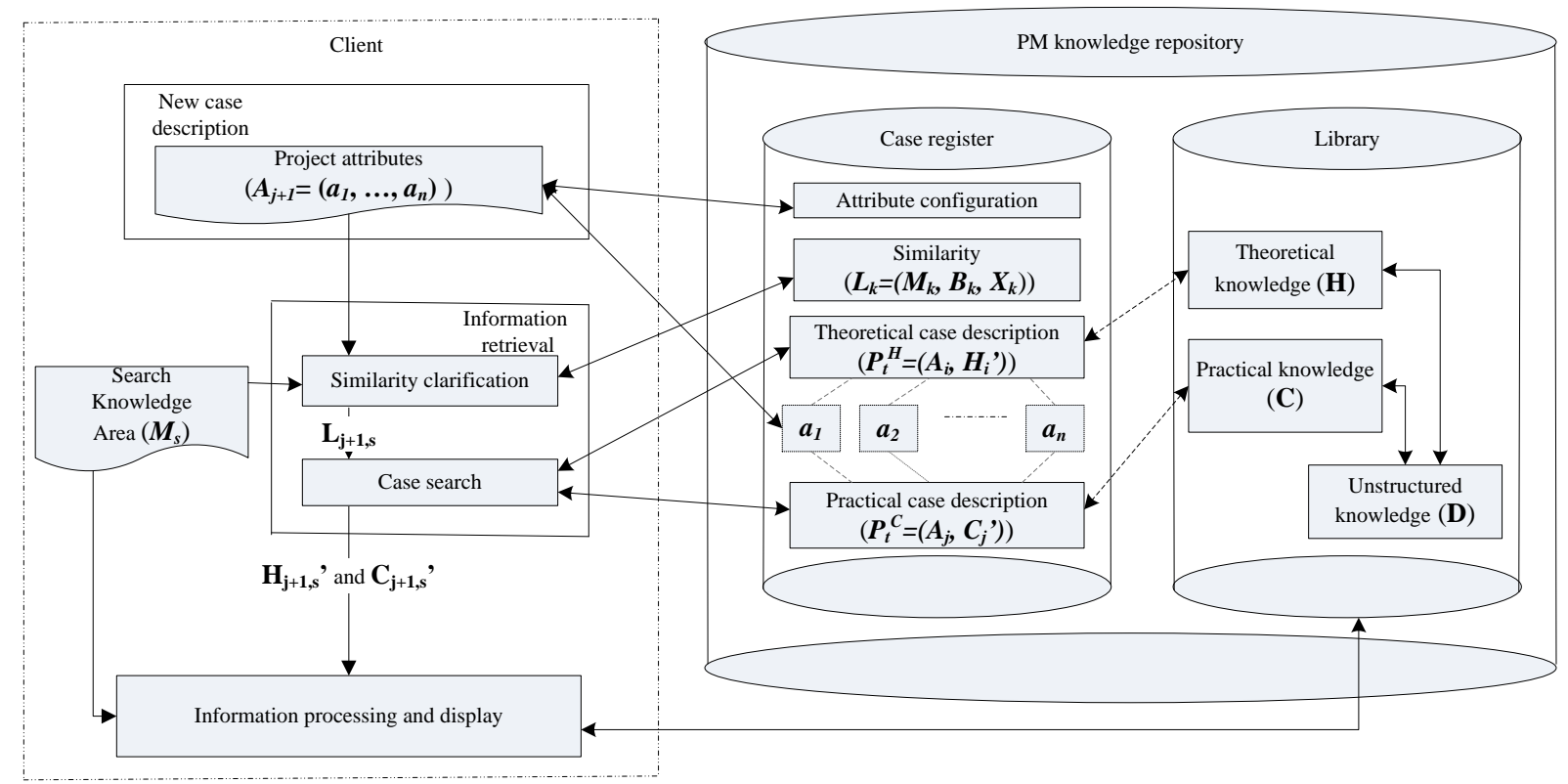

Fig. 1. Architecture of PM knowledge retrieval 


\section{Project attribute}

In the proposed architecture the project attributes are main element in the PM knowledge classification and the similar case search (Fig.1). The default set of attributes and attribute values are established in this architecture, but predefined configuration can be edited, extended or reduced according to needs and area. During the similar case selection each attribute is defined the similarity measurement $x_{i}\left(\mathrm{X}_{\mathrm{k}}=\left(x_{1}, \ldots, x_{n}\right), n\right.$ is count of attribute) that depends of the knowledge search area $M_{k}$ and the knowledge type $B_{k}$ (theoretical or practical). These similarity measurements are also configurable.

The characteristics of project and project environment have been defined with the project attributes. Description of these characteristics can be found in general PM methodologies such as PMBOK [4] and PRINCE2 [5]. In PMBOK the project environment information has been found as input data to a project charter development process or has been defined in the project charter. In [5] that describe PRINCE2 one charter is devoted to the project environment.

Information from PM methodologies PMBOK and PRINCE2 and existent project classifications [13] [14] [16] have been used for definition of the general project classification attributes.

\section{Result}

The general project attributes obtained from the methodologies and the existent classifications have been collected into Table 1 . The resulting set of project attribute includes eighteen attributes that can be divided into six groups: type, product, size, organization, guidance and management/planning approach. The project type defines the way in which the project is being implemented and what kind of customer. The project product attributes are defined by product, it areas and how it is obtained. The project size is described by complexity, team size, project budget and duration. To describe the project execution organization should indicate its structure, size and basic work area. The project organization size can be measured with count of employers or turnovers. The guidance is three types: the PM methodologies, frameworks and standards; the government rules; and the project product related standards. The approach group attributes define the PM lifecycle and the estimation and cost approaches. The project attribute values must be clearly defined and classified in order to prevent the subjective assessment. For example, for the team size description better use classified values 'less than 10' and '10 and more' than values 'small' and 'large'. Examples of the attribute values are given in Table 1 .

\section{Discussion}

To demonstrate the project classification using the set of project attributes twenty-two projects have been classified. All of these projects are from the information technology area and have been developed in Latvia.

Further project classification according to the project attributes groups is analyzed.

According to the project type and client, projects are divided in five groups:

1) Outsourcing + government (9 projects);

2) In-house + commercial (1 project);

3) In-house + private (4 projects);

4) Outsourcing + private (6 projects);

5) In-house + government ( 2 projects).

The product in all projects belongs to the information technology area and the result is software. These projects have different project actions. According to the project product, the reviewed projects are divided in five groups:

1) Improvement + software + IT (7 projects);

2) Development + software + IT (11 projects); 
3) Development and implementation + software + IT (2 projects);

4) Implementation + software +IT (1 project);

5) Development + software and process + IT (1 project).

Table 1.

Project classification attributes

\begin{tabular}{|c|c|c|c|c|}
\hline Attribute & PMBOK & PRINCE2 & $\begin{array}{c}\text { Other } \\
\text { resource }\end{array}$ & Possible values \\
\hline \multicolumn{5}{|c|}{ Project type } \\
\hline Project type & $\mathrm{X}$ & $\mathrm{X}$ & & $\begin{array}{l}\text { Outsourcing / In-house / Offshore } \\
\text { National / International } \\
\text { Internal / External }\end{array}$ \\
\hline Client & $\mathrm{X}$ & $\mathrm{X}$ & {$[16]$} & $\begin{array}{c}\text { Government / Private / } \\
\text { Commercial }\end{array}$ \\
\hline \multicolumn{5}{|c|}{ Project product } \\
\hline Project action & $\mathrm{X}$ & $\mathrm{X}$ & [13] & $\begin{array}{l}\text { Development / Maintenance / } \\
\text { Improvement/ Implementation }\end{array}$ \\
\hline Project product & $\mathrm{X}$ & $X$ & [13] & Product / Service / Process \\
\hline Area & $\mathrm{X}$ & $\mathrm{X}$ & [13] & $\begin{array}{l}\text { Classified values (e.g., IT, } \\
\text { Construction, Research etc.) }\end{array}$ \\
\hline \multicolumn{5}{|c|}{ Project size } \\
\hline Complexity & & $\mathrm{X}$ & [13] & $\begin{array}{l}\text { Mono- / Multi-discipline } \\
\text { With / Without branches }\end{array}$ \\
\hline Team size & $\mathrm{X}$ & $\mathrm{X}$ & [13] & Scalar \\
\hline Project budget & $\mathrm{X}$ & $\mathrm{X}$ & [16] & Scalar \\
\hline Duration & & $\mathrm{X}$ & {$[16]$} & Scalar \\
\hline \multicolumn{5}{|c|}{ Project organization } \\
\hline $\begin{array}{l}\text { Project } \\
\text { organization } \\
\text { structure }\end{array}$ & $\mathrm{X}$ & & MSF & $\begin{array}{c}\text { Functional / Weak matrix / } \\
\text { Balanced matrix / Strong matrix / } \\
\text { Project }\end{array}$ \\
\hline Organization size & & $\mathrm{X}$ & & Scalar \\
\hline Organization area & & $\mathrm{X}$ & & $\begin{array}{l}\text { Classified values (e.g., IT, } \\
\text { Construction, Research etc.) }\end{array}$ \\
\hline \multicolumn{5}{|c|}{ Guidance } \\
\hline $\begin{array}{l}\text { Management } \\
\text { methodologies }\end{array}$ & $\mathrm{X}$ & $\mathrm{X}$ & MSF & $\begin{array}{l}\text { Classified values (e.g. PMBOK, } \\
\text { PRINCE2, RUP, MSF, Agile, } \\
\text { SCRUM, CMMI, ITIL, ISO9001) }\end{array}$ \\
\hline Government rule & $\mathrm{X}$ & $\mathrm{X}$ & MSF & Classified values \\
\hline $\begin{array}{l}\text { Product related } \\
\text { standards }\end{array}$ & $\mathrm{X}$ & $\mathrm{X}$ & MSF & Classified values \\
\hline \multicolumn{5}{|c|}{ Management/planning approach } \\
\hline PM lifecycle & $\mathrm{X}$ & & & $\begin{array}{l}\text { Classified values (e.g. Waterfall, } \\
\text { Iterative, Spiral, Agile) }\end{array}$ \\
\hline $\begin{array}{c}\text { Estimation } \\
\text { approach }\end{array}$ & & $\mathrm{X}$ & & Expert / Functional point \\
\hline Cost approach & & $\mathrm{X}$ & & $\begin{array}{c}\text { Contract price / Fixed price per } \\
\text { unit }\end{array}$ \\
\hline
\end{tabular}

The project size is described with four attributes where three attribute - team size, budget and duration - are scalar values and it values should be grouped into intervals. The team size 
values have been divided into two intervals: 'less than seven' and 'seven and more'. Analyze budget attribute values have been divided into five intervals: 'less than 10000 '; '10 000 - 50 000', '50 000 - 100 000', '100 000 - 500 000', '500 000 and more'. The project duration values have been divided into four intervals: 'less than six months', 'six month to a year', 'from a year to two years' and 'more than two years'. The reviewed projects are divided into eleven groups by the project size:

1) Multi-discipline + less than $7+$ more than $500000+$ more than 2 years $(2$ projects);

2) Multi-discipline + less than $7+100000-500000+6$ months to a year $(1$ project);

3) Multi-discipline +7 and more + more than $500000+$ more than 2 years $(1$ project);

4) Multi-discipline +7 and more $+100000-500000+6$ months to a year $(1$ project);

5) Mono-discipline +7 and more $+10000-50000+$ less than 6 months ( 1 project);

6) Mono-discipline +7 and more $+50000-100000+1-2$ years ( 1 project);

7) Mono-discipline +7 and more $+10000-50000+6$ months to a year ( 1 project);

8) Mono-discipline +7 and more $+50000-100000+6$ months to a year $(1$ project);

9) Mono-discipline + less than $7+10000-50000+$ less than 6 months ( 5 projects);

10) Mono-discipline + less than $7+10000-50000+6$ months to a year ( 4 projects);

11) Mono-discipline + less than $7+$ less than $10000+$ less than 6 months (4 projects).

The project organization is described with three attributes, these attributes characterizes project implementation organization. The organization size attribute is scalar values that have been measured with employer count and have been divided into two intervals: 'less than 100' and ' 100 and more'. According to the project organization the reviewed projects are divided in eight groups:

1) Project +100 and more + IT (7 projects);

2) Project + less than $100+$ IT (6 projects);

3) Project + less than $100+$ education $(1$ project $)$;

4) Project +100 and more + manufacture (1 project);

5) Individual + less than $100+$ IT (1 project);

6) Functional +100 and more + energy (1 project);

7) Functional + less than $100+$ government ( 2 projects);

8) Matrix + 100 and more + IT (2 projects).

The reviewed projects according to the used guideline are divided in eight groups:

1) None (9 projects);

2) ISO $9001: 2008$ (5 projects);

3) ITIL + ISO 9001:2008 (2 projects);

4) $\mathrm{MSF}+\mathrm{PMBOK}+\mathrm{CMMI}+\mathrm{ISO} 9001: 2008$ + LVS (1 project);

5) ISO 9001:2008 + LVS (2 projects);

6) ISO 9001:2008 + EC rule + IEEE + LVS (1 project);

7) ISO 9001:2008 + ITIL + CMMI (1 project);

8) Scrum (1 project).

All twenty two projects use expert estimation approach, but they differ in the PM lifecycle and the cost approach. The reviewed projects are divided into seven groups by the used approaches:

1) Evolutionary + expert estimation + fixed price for unit cost (3 projects);

2) Evolutionary + expert estimation + contract price cost (2 projects);

3) Waterfall + expert estimation + contract price cost (4 projects);

4) Waterfall + expert estimation + fixed price for unit cost (9 projects); 
5) Iterative + expert estimation + contract price cost ( 2 projects);

6) Agile + expert estimation + fixed price for unit cost (2 projects).

Full result of the reviewed project classification is shown Table 2. Explanation of values for the attribute groups is given in text above.

The project classification result shows that among the twenty two reviewed projects if they have been compared after all eighteen attributes there are no two similar projects. However, usually similar projects are not searched according to all attributes, but only after those that affect the searched knowledge area. For example, planning project activities user might only interest information about projects with similar product, project size, approaches and guidance. After these four groups of attributes can be considered that similar are project 6 and 7. According to project type, product and size similar are project 7 and 21 . The project similarity can be evaluated by the various subsets of attributes.

Table 2.

\section{Project classification}

\begin{tabular}{|c|c|c|c|c|c|c|}
\hline \multirow{2}{*}{$\begin{array}{c}\text { Project } \\
\text { ID }\end{array}$} & Type & Product & Size & Organization & Guidance & Approach \\
\hline 1 & 1 & 1 & 1 & 1 & 2 & 1 \\
\hline 2 & 1 & 2 & 3 & 1 & 2 & 2 \\
\hline 3 & 1 & 2 & 2 & 1 & 2 & 3 \\
\hline 4 & 2 & 1 & 1 & 1 & 2 & 4 \\
\hline 5 & 3 & 2 & 5 & 6 & 3 & 4 \\
\hline 6 & 1 & 2 & 9 & 8 & 1 & 4 \\
\hline 7 & 4 & 2 & 9 & 2 & 1 & 4 \\
\hline 8 & 4 & 3 & 10 & 2 & 1 & 2 \\
\hline 9 & 1 & 1 & 4 & 2 & 4 & 5 \\
\hline 10 & 1 & 1 & 10 & 1 & 5 & 6 \\
\hline 11 & 4 & 2 & 11 & 2 & 1 & 3 \\
\hline 12 & 3 & 4 & 11 & 3 & 1 & 4 \\
\hline 13 & 4 & 2 & 6 & 2 & 1 & 3 \\
\hline 14 & 3 & 1 & 11 & 8 & 1 & 4 \\
\hline 15 & 5 & 3 & 11 & 7 & 1 & 1 \\
\hline 16 & 3 & 2 & 9 & 4 & 1 & 1 \\
\hline 17 & 3 & 1 & 7 & 2 & 6 & 3 \\
\hline 18 & 1 & 1 & 9 & 1 & 2 & 6 \\
\hline 19 & 5 & 5 & 10 & 7 & 7 & 4 \\
\hline 20 & 1 & 2 & 8 & 1 & 5 & 4 \\
\hline 21 & 4 & 2 & 9 & 5 & 8 & 2 \\
\hline 22 & 1 & 2 & 10 & 2 & 3 & 4 \\
\hline
\end{tabular}

\section{Conclusion}

The project attributes is one of the important input data in the PM knowledge retrieval. This paper defines the set of the main project attributes that can be used as basis for the classification of any project. These defined attributes will be used as the default set of attributes in the PM knowledge retrieval. To obviate the subjective assessment values of this attributes must be clearly defined and classified.

The main task for the attributes in the PM knowledge retrieval is to ensure search of similar project by comparison of the attribute values. Not always the similar projects are being sought for full set of attributes, but the subset of affected attributes is defined for the each search knowledge area. 


\section{Acknowledgment}

This research has been supported by the European Social Fund within the project "Support for the implementation of doctoral studies at Riga Technical University".

References
1. Gasik, S. A model of project knowledge management. Project Management Journal, vol. 42, no.2, 2011, p.23-44

2. Ali, A.S.B., Anbari, F.T., Money W.H. Impact of organizational and project factors on acceptance and usage of project management software and perceived project success. Project Management Journal, vol. 39, no.2., 2008, p.5-33

3. Dvir, D., Raz, T., Shenhar, A.J. An empirical analysis of the relationship between project planning and project success. International Journal of Project Management, vol. 21, 2003, p.89-95.

4. Project Management Institute. A Guide to the Project Management Body of Knowledge (PMBOK® Guide) 4th edition. Project Management Institute, 2008

5. Hedeman, B., Heemst, G.V.V., Fredriksz, H. Project management based on PRINCE2 (Best Practice), 3rd edition. Van Haren Publishing, 2006

6. Gibbs, D. Project management with the $\operatorname{IBM}(\mathrm{R})$ Rational Unified Process $(\mathrm{R})$ : lessons from the trenches. IBM Press, 2006.

7. Turner, M.S.V. Microsoft Solutions Framework essentials: building successful technology solutions. Microsoft Press, 2006

8. Schwaber, K. Agile project management with Scrum. Microsoft Press, 2004

9. The 9000 Store. ISO 9001:2008 Quality Manual. The 9000 Store, 2008

10. Dymond, K.M. A Guide to the CMMI: Interpreting the Capability Maturity Model Integration. Process Transition International Inc., 2005

11. Brand, K., Boonen, H. IT Governance based on Cobit 4.1 - A Management Guide (ITSM Library). Van Haren Publishing, 2007

12. Bon, J.V. ITIL® V3: A Pocket Guide (ITSM Library). Van Haren Publishing, 2007

13. Dvir, D. In search of project classification: a non-universal approach to project success factors. Research Policy, vol. 27, 1998, p.915-935

14. Shenhar, A.J. One size does not fit all projects: Exploring classical contingency domains. Management Science, vol. 47, 2001, p.394-414

15. Turner, R., Cochrane, R.A. The goals and methods matrix: Coping with projects with ill-defined goals and/or methods of archiving them. International Journal of Project Management, vol.11, 1993, p. 93-102

16. Yang, H-L., Wang, C-S. Recommendation system for software project planning one application of revised CBR algorithm. Expert Systems with Applications, vol. 36, 2009, p.8938-8945

17. Bērziša, S., Grabis J., A framework for knowledge-based configuration of project management information systems. Information technologies' 2001 - Proceedings of the $17^{\text {th }}$ International Conference on Information and Software Technologies, Kaunas, Lithuania, Kaunas University of Technology, 2001, p.31-38

18. Aamodt, A., Plaza, E. Case-based reasoning: Foundational issues, methodological variations, and system approaches. AI Communications, vol. 7, 1994, p.39-59

19. Bērziša, S. XML-based specification of the project management domain and its application. Databases and Information Systems VI - Selected Papers from the Ninth International Baltic Conference DB\&IS 2010, Riga, Latvia, IOS Press, 2011, p.213-226. 